\title{
SEXUAL HARASSMENT OR DELECTATION IN SMES IN THE CONSTRUCTION INDUSTRY
}

\author{
Takupiwa Nyanga \\ Department of Human Resource Management, Julius Nyerere School of Social Sciences, \\ Great Zimbabwe University, Masvingo, Zimbabwe \\ takupiwa@gmail.com \\ Andrew Chindanya \\ Robert Mugabe School of Education, \\ Great Zimbabwe University, Masvingo, Zimbabwe \\ andychindanya@gmail.com
}

\begin{abstract}
Sexual harassment at workplaces significantly infringes the fundamental rights of both men and women to gender equality and social justice. The purpose of this study was to investigate whether sexual harassment at workplaces significantly affects job satisfaction among workers in SMEs in the construction industry. The study employed a purely qualitative research methodology to carry out the study. Convenience sampling technique was employed to select the 50 (fifty) participants who took part in the study. All the 50 workers who participated in the study were drawn from ten (10) SME construction companies in the city of Masvingo in Zimbabwe. Data was solicited using a 14-item face to face interview guide which was developed by the researcher. Data was analyzed and interpreted using the thematic data analysis method. The study established that sexual harassment at workplaces directly and indirectly affects workers in the construction industry's job satisfaction levels. Sexual harassment at workplaces results in decreased work performance; increased absenteeism, loss of job or career, loss of income, being objectified and humiliated, loss of trust in the types of people that occupy similar positions as the harasser or his or her colleagues. Sexual harassment also leads to psychological disorders of victims. All the effects of sexual harassment negatively affect job satisfaction for workers in the construction industry. The study recommended that all arms of government responsible for enforcing sexual harassment laws and regulations should closely monitor sexual harassment activities in organizations and impose prohibitive sanctions upon the perpetrators. Organizations should also punish all the perpetrators of sexual harassment at workplaces.
\end{abstract}

Keywords: Sexual harassment, job satisfaction, SMEs, Construction industry.

\section{INTRODUCTION}

Job satisfaction has been a subject of much interest among researchers over a very long time. Several studies (Nyanga et al., 2012, Nyanga et al., 2018, Nyanga, 2018) have been mounted to establish the effects of job satisfaction on organizational performance, organizational citizenship, labor turnover, 
absenteeism and other essential business constructs. Job satisfaction has the potential of making an organization earn a strong competitive advantage from its human capital. It is essential for organizations to ensure that their workers possess the right attitude towards their work so that they become prepared to expend their energy towards meeting set organizational goals. Studies (Nyanga et al., 2012) established that job satisfaction is determined by several factors such as salaries and wages, leadership style, availability of tools of the trade, working conditions and others. While it has been viewed as critical for organizations to address job satisfaction challenges in SMEs there is a growing concern over the seemingly increase in social, work, political and technological constructs that impede job satisfaction. Sexual harassment has become one of the constructs that significantly affect the management of the human capital in SMEs in Zimbabwe and beyond. Sexual harassment is increasingly becoming a common feature at various workplaces especially in the construction industry. Society however seem to be slowly accepting it as a normal standard of operation. Society does not aggressively combat sexual harassment by enforcing laws and regulations put in place by government to combat and minimize the occurrence of sexual harassment. The effects of sexual vary depending on the harassed individual, severity of the harassment and the values and ethos of society. For purposes of ensuring that employees are appropriately satisfied it is essential for job satisfaction researchers to investigate the effects of all key job-related constructs that have the potential of derailing job satisfaction such as sexual harassment at the workplace. The purpose of this research was to investigate whether sexual harassment significantly affect workers' attitude towards their work.

\section{LITERATURE REVIEW}

According to Nyanga et al. (2018) "Job satisfaction refers to workers' responses to the attributes of their jobs. The responses are personal and have cognitive (evaluative), affective (or emotional), and behavioral components." To add more Medgyesi and Zolyomi (2016) argue, "Satisfaction with a job comes from a comparison of the characteristics of the actual job and a person's views about the characteristics the job ought to have." Job satisfaction therefore refers to workers' attitude towards their work and its attributes. It is the extent to which employees like or dislike their work. Employees either develop a positive or negative attitude towards their work depending on several factors such as salaries and wages, general conditions of service, leadership style and others. Sexual harassment has been a subject of debate among academics and researchers (American Association of University Women, 2006; Bingham and Gansler 2002; Parmar, 2014; Patel et al., 2017) because of the extent it affects operations of the management of the human capital. The United Nations through the Convention 19 on the Elimination of all Forms of Discrimination against Women views sexual harassment of women as: 
"such unwelcome sexually determined behavior as physical contact and advances, sexually colored remarks, showing pornography and sexual demands, whether by words or actions. Such conduct can be humiliating and may constitute a health and safety problem; it is discriminatory when the woman has reasonable ground to believe that her objection would disadvantage her in connection with her employment, including recruitment or promotion, or when it creates a hostile working environment." Furthermore, the Equal Employment Opportunity Commission (1980) defines sexual harassment as: "Unwelcome sexual advances, requests for sexual favors, or other verbal or physical conduct of a sexual nature when:1. Submission to such conduct was made either explicitly or implicitly a term or condition of an individual's employment, 2. Submission to or rejection of such conduct by an individual was used as the basis for employment decisions affecting such individual, or 3 . Such conduct has the purpose or effect of unreasonably interfering with an individual's work performance or creating an intimidating, hostile, or offensive working environment." From the above definitions it can be deduced that sexual harassment refers to any verbal or non-verbal, physical or non-physical used to divert a victim's sexual status against his or her will which consequently lead to the victim feeling denigrated, inferior and his or her dignity spoiled. Both men and women can be victims and/or perpetrators of sexual harassment at workplaces. Legislation in Zimbabwe such as the Labor Act Chapter 28:01, and The Constitution of Zimbabwe of 2013 provides that men and women are regarded as equal hence any action taken by the other to demand sexual favors from a workmate or a subordinate is also viewed as sexual harassment. Sexual harassment at workplaces according to both local and international labor laws include such behavior as making sexually suggestive jokes, remarks, showing pornographic videos and pictures, starring at workmate and physical contact.

In consistence with Article 222-33 of the French Criminal Code, for purposes of this study sexual harassment at the workplace shall be defined as, a means of giving orders, threats, showing pornographic pictures and videos, making sexual suggestive remarks in order to obtain sexual favors, by a person with authority or power over the victim. This implies that the harasser can either be someone with authority on the victim or coworker of the same rank. Studies (Arnqvist and Rowe, 2005; Parmar, 2014; Kamir, 2005) have argued that sexual harassment happens when a worker is exposed to repeated acts which leads to the degradation of the victim's conditions of employment. The behavior of the harasser can undermine the victim's reputation, rights and dignity, jeopardize the victim's profession and affect psychological and physical status of an employee. According to Markson (2017) there are basically two common forms of sexual harassment at workplace, which are 'quid pro quo' where the harasser uses 'this for that or something for something' strategies to demand sexual favors from a workmate or subordinate in return for employment favors such as higher salary and promotion. A study 
by Nyanga (2019) established that employee resourcing was marred by several challenges one of which is sexual harassment and favoritism. Employees who hold positions of authority sexually bribe and coerce their subordinates by promising them employment benefits. Besides the 'quid pro quo' the other form of sexual harassment at workplace is creating a hostile work environment for the victim by illtreating the employee, shouting at the employee, and awarding him/her lower performance appraisal scores. The strategy is to make the victim buy peace by acceding to the sexual demands of the harasser or offering sexual favors to the one controlling the work environment. For instance, in the construction industry a foreman or supervisor may ask the bricklayer to demolition what he/she will have built purporting it to be wrongly done. To seek peace the victim may accede to the sexual demands of the harasser. Such behavior constitutes sexual harassment since the supervisor is making the work environment harsh and unattainable for the worker.

A study by Markson (2017) established that sexual harassment was prevalent in several construction industries throughout the world. He indicated that the most affected groups of people were women mainly because the construction industry is dominated by men. Junior officers were also the most affected probably by virtue of their positions which do not command a lot of authority. He observed that only a few men were sexually harassed by either their female or male counterparts. The study established that sexual assaults infringe the fundamental right of employees. His findings were consistent with Article 14 of the Constitution of India which says that sexual harassment infringes a woman to gender equality and her right to life and live with dignity. Workers especially men and those who hold positions of authority make sexually colored remarks, unwelcome sexual gesture or behavior such as physical contact, showing pornography, demand sexual favors and any other unwelcome physical, verbal/non-verbal conduct that is sexual in nature. Such behavior is discriminatory, restrict the victim the liberty to make his/her sexual practices decisions, violates and infringes a worker's right to respect and privacy. (Kamir, 2005) argues that the law discourages intimidation or retaliation that promotes sexual assaults at workplaces. According to Boland (2002) every year, sexual harassment costs hundreds of millions of dollars in lost educational and professional opportunities, mostly for girls and women.

Studies on job satisfaction (Nyanga, 2018; Nyanga et al., 2012; Nyanga et al., 2018) established that job satisfaction is caused by salaries and wages, working conditions, labor relations, leadership style, opportunities for promotion and career growth, and many others. Investigations on the relationship between job satisfaction and organizational citizenship, organizational performance, salaries and wages, working conditions and leadership styles were made by several scholars. The researcher however did not come across a study that investigated the effects of sexual harassment on job satisfaction in the construction industry in a developing country such as Zimbabwe. There is paucity of 
literature on the relationship between the two constructs, yet the construction industry is marred by reported or unreported sexual harassment challenges. The aim of this study was there to fill this knowledge gap by investigating the effects of sexual harassment on the workers' attitude towards their work.

\section{METHODOLOGY}

The study employed a purely qualitative research approach and used a multiple case study design to carry out the study. 10 SMEs in the construction industry from five growth points in the Midlands, Masvingo and Matabelaland South provinces were selected to participate in the study. The 10 SMEs were selected using the snow balling sampling technique. From the ten organizations 50 participants were selected using convenience sampling technique. The researcher however, faced some difficulties in reaching the workers since they did not have fixed workstations. Workers would be moved from one construction site to the other or from one district to the other depending on the availability of work and the trade required at that site. The researcher then opted to use convenience sampling where he would collect data from the participants, he would find at the workstation.

In order to access the information required for the study, the researcher developed a 14-item interview guide with two distinct sections. The first section was on personal information where participants would fill in their biographical information. The second section comprised questions which sought to establish the state and prevalence of sexual harassment in the construction industry and how it affects job satisfaction. All the interviews were face to face interviews and were conducted at workers' construction sites or workshops from August 2019 to November 2019. The collected data was audio recorded and recorded verbatim as the respondents gave their responses. Data was analyzed using thematic data analysis method where themes were developed as the researcher went through the transcribed notes and listen to audio recorded data from the participants.

\section{FINDINGS}

TABLE 1. BIOGRAPHICAL DATA

\begin{tabular}{|l|l|l|l|l|}
\hline Gender & Female & $\mathrm{n}=19$ & Male & $\mathrm{n}=31$ \\
\hline Marital status & $\begin{array}{l}\text { Single } \\
(\mathrm{n}=16)\end{array}$ & $\begin{array}{l}\text { Married } \\
(\mathrm{n}=17)\end{array}$ & $\begin{array}{l}\text { Widowed } \\
(\mathrm{n}=7)\end{array}$ & $\begin{array}{l}\text { Divorced } \\
(\mathrm{n}=13)\end{array}$ \\
\hline $\begin{array}{l}\text { Educational } \\
\text { qualifications }\end{array}$ & $\begin{array}{l}\text { Ordinary level \& } \begin{array}{l}\text { Apprenticeship/Diploma/certificates } \\
\text { below } \\
(\mathrm{n}=14)\end{array} \\
\begin{array}{l}5 \text { years \& below } \\
(\mathrm{n}=20)\end{array}\end{array}$ & $\begin{array}{l}6-10 \text { years } \\
(\mathrm{n}=17)\end{array}$ & $\begin{array}{l}\text { Post Grad. } \\
\text { Degree } \\
(\mathrm{n}=6)\end{array}$ \\
\hline Work Experience & $\begin{array}{l}\mathrm{n}=10 \\
11-15 \text { years } \\
(\mathrm{n}=10)\end{array}$ & $\begin{array}{l}15 \text { years } \\
\text { and above } \\
(\mathrm{n}=3)\end{array}$ \\
\hline
\end{tabular}

Source: Authors, based on collected data 
Expectedly, the construction industry is dominated by men, but there is a remarkable increase in the number of women who join the industry as bricklayers, plumbers, electricians and welders. In terms of marital status, the married and single categories were almost at par and they dominated the other categories. The widowed category garnered the least number of participants. Biographical data also shows that most of the artisans in SMEs in the construction industry were appropriately skilled for their jobs since 36 out of 50 participants were skilled and only 14 were semi-skilled. 30 participants had a work experience of over 6 years which is very good for the industry and the quality of work. The long service work experience was also good for the study because the participants had full appreciation and comprehension of what was taking place at their organizations in relation to sexual harassment and job satisfaction.

The study revealed that the government of Zimbabwe has put in place adequate and effective laws, rules and regulations and encouraged organizations to put in place policies that protect workers from all forms of sexual harassment at workplaces. The Constitution of Zimbabwe and the Labor Act makes it explicitly clear that it is an offence to sexually harass another person or workmate. The sanctions that are imposed on all the harassers are prohibitive enough to eradicate or minimize workplace related sexual harassment. One of the participants commended the government for putting in place and enforcing laws that prohibit sexual harassment when he said, "The Government is applauded for putting in place laws that minimize sexual harassment at workplaces. The only challenge is that most victims do not report all the forms of harassments to the responsible authorities hence some harassers escape the sanctions." The laws that address sexual harassment issues in Zimbabwe are in sync with the 2002 amendment by the European Union Council and Parliament of the 1976 Council Directive on the equal treatment of men and women in employment to prohibit sexual harassment in the workplace. The amendment referred sexual harassment as a form of sex discrimination and violation of dignity of women.

The study also revealed that sexual harassment at emerging construction organizations was generally high, but it is rather subtle. It was reported that most sexual harassment activities and behaviors go unreported because some victims do not have adequate knowledge on the reporting platforms and the consequences that were associated with reporting such cases. Sexual harassment at workplaces has been mystified because workers have different and conflicting perceptions and comprehension of sexual harassment. One of the respondents remarked, "Not all sexually colored remarks, physical contact and showing sexually stimulating videos and pictures constitute sexual harassment because some of the purported victims enjoy it but only pretend not to be liking it since it is taboo in African culture." Participant 47 said "We make sexually related jokes at our workplace but personally I do not consider it as harassment because all of us will be enjoying it except a few married ladies who are shy 
to talk about sexual matters." This implies that not all forms of sexual assaults as defined in the legislation in Zimbabwe such as the Labor Act Chapter 28;01, the Constitution of Zimbabwe amendment 21 of 2013 is regarded as sexual harassment by all employees. Participant 23 said, "There are no rape cases and major sexual assaults that have reported and observed at our organization and in the construction industry for the past five years. The only thing, which the law regard as sexual harassment is the sharing of sexually colored remarks, videos and pictures that we do as we do our work or using social media such as WhatsApp. Almost all the workers enjoy it and only a few are offended." It implies that not all sexual harassment acts espoused in legislation are regarded by workers in the construction industry as sexual harassment. Some purported sexual harassment acts are classified as the language of the trade. Most workers do not consider some sexual harassment issues as severe enough to warrant for a legal claim or reporting to management. The findings are partially consistent with Markson (2017) who argues that sexual harassment was a common phenomenon in workplaces throughout the world. While it is acknowledged that there are some forms of sexual harassment activities in the construction industry, its severity is very low.

While sexual harassment of women by men is the most debated and publicized one, the findings of this study revealed that both men and women can be harassers or victims of sexual harassment and suffer the same consequences. The only difference is that most of the reported cases of sexual harassment are reported by women. One of the respondents said, "Men in the construction industry are regularly sexually harassed by their female counterparts but because of their cultural background they choose not to report women harassers." This implies that both men and women in the construction industry have the potential of harassing each other. Some female workers behave in a manner that make sexual harassment easier by the way they dress and acting 'nice and good' to their supervisors and co-workers which consequently make them become targets. The niceness and goodness of an employee may motivate coworkers or supervisors to say lewd and show them pornographic materials. However, some scholars (Dershowitz and Volokh, 2009) have criticized sexual harassment laws for imposing on the right to free speech. Restricting people from sharing notes, ideas and thoughts that are sexual in nature in some way deprive people of their right to freedom of speech. It should however be noted that the right to freedom of speech should not infringe other people such as workers' right be treated in a respectful and dignified manner. Some feminist groups criticize sexual harassment policy as helping maintain archaic stereotypes of women as "delicate, asexual creatures" who require special protection. The study also showed that there are some recent trends towards more revealing clothing and permissive habits in the construction industry that have developed a more sexualized work environment, where some types of communication are erroneously categorized as harassment, yet they are a mere reaction to greater 
sexualization in everyday environments. The most prevalent forms of sexual harassment include making unwelcome sexually colored remarks, sharing sexually colored comments, showing pictures and videos through the social media, quid pro quo, staring at a victim, repeatedly making unwanted sexual advances, repeatedly following the victim, pursues, accosts another person, repeatedly making telephone calls to the harassed person and loitering near a place where the harassed will be working. All the respondents reported that sexual harassment at workplaces results in the decrease in work performance and increases the rate of absenteeism and labor turnover. For example, in quid pro quo type of sexual harassment where the job benefits such as promotion and salary increase are directly tied to a worker acceding to unwelcome sexual moves may reduce worker concentration. Quid pro quo type of harassment can also be observed when a worker decides to withhold or ignore professional opportunities that emerge in his/her organization because of the supervisor or any other person with a position of authority's submission to verbal, nonverbal or physical conduct of sexual nature. This kind of harassment makes an employee to lose a job opportunity or income. The loss of income and job opportunity adversely affects the worker's job satisfaction. Participant 9 said, "I work for a construction company with eleven workers, I am planning to leave the company because my supervisor and workmates always make some unwelcome sexual advances to me and at times they send me sexually suggestive videos and pictures through the social media." Participant 29 remarked, "I am no longer satisfied by work because my supervisor wants me to extend sexual favors to him so that I can be either promoted or get a higher salary." It implies that job satisfaction is adversely affected by sexual harassment at workplaces in the construction industry. The findings are consistent with Nyanga et al. (2018) who argued that salaries and wages and financial benefits positively influence job satisfaction, hence depriving workers' salaries and wages leads to low job satisfaction.

The study also found out that sexual harassment adversely affects job satisfaction among workers by objectifying and humiliating the worker. A harassed employee's personal life is offered for public scrutiny. The harassed worker's lifestyle, his/her dress become the main subjects of gossip and debate at the workplace. Public scrutiny of an employee makes him/her develop psychological disorders which consequently affect the extent to which workers like or dislike their work. Participant 1 said, "An employee's psychological stability is distorted because he/she will have been made publicly sexualized since some workers may analyses the victim to find out whether she/he is worth affecting the offender's profession." Sexual harassment at the workplace defames the victim's character and reputation which consequently make the employee dislike his/her work. Some employees may call her names such as 'pfambi' (prostitute) and regard her as a person of loose morals, which is inconsistent with the ethos and values of Zimbabwean norms and values. Instead of the victim getting support from his/her workmates to have the perpetrator to account for his/her behavior he/she ends up receiving a sanction for reporting 
the case. Sexual harassment causes psychological and health consequences to both the harasser and the victim. The psychological disorders include depression, anxiety, nightmares, guilt conscience, lack of concentration, sexual disorders, headaches, alcoholism and eating disorders. All the psychological disorders adversely affect job satisfaction. Respondent 23 said, "After I was harassed I felt betrayed, my rights violated, powerless. My blood pressure then increased, I developed low self-esteem and my job satisfaction levels drastically went down." This implies that there is a strong relationship between job satisfaction and sexual harassment at workplaces in the construction industry.

Sexual harassment also makes victims lose confidence and people who occupy similar positions to that of the person who will have harassed him/her. The victim may also lose trust in the environment or a similar work environment where the sexual abuse occurred. For instance, the victim may no longer be comfortable to visit his/her supervisor's office if the harassment will have occurred in the supervisor's office or a similar environment. Loss of trust in workmates and supervisors has been observed by preceding studies (Nyanga et al/, 2012, Nyanga, 2018, Markson, 2017) as one of the major impediments to job satisfaction. Participant 36 remarked, "My boss/instructor subjected me to unwelcome sexual remarks, physical contact and showed me offensive sexual materials almost all the time I visited his office. This offended me but I could not report it because I was afraid of losing my job. I developed a negative attitude towards him and the work." This shows that sexual harassment makes the work environment hostile to the extent that workers start to suffer from presenteeism and other psycho-social disorders. Work conditions and relations with coworkers and members of the management team play a major role in boosting workers' job satisfaction. Employees in the construction industry are subjected to sexual abusive remarks to the extent that they end up disliking their workplaces. There is diversity of employees in the construction some come from a religious background which regard any form of sexual abusive utterances not only as sexual harassment but sin. Such groups of workers lose trust in leaders or workmates who make such remarks and dislike the work environment where such remarks are made. It should however be noted that some groups of employees especially the young generation, the divorced and the single enjoy the 'sexual harassment' in the form of receiving sexually colored remarks, photographs, videos and comments from their colleagues. According to this group of people what legislation refer to as sexual harassment is actually a job satisfaction enhancer since people like it and enjoy the practice. Most participants only referred rape as a meaningful sexual harassment that warrant the attention of law enforcement agencies. According to the Zimbabwean laws, culture and ethos it is morally wrong and unacceptable for people to share sexually colored remarks, pictures and videos hence workers in the construction industry should abide by the acceptable norms and values of their societies. 
Sexual harassment at work makes victims develop extreme stress which prohibits them from socializing well with their spouses, friends and relatives. High levels of stress can sometimes degenerate into divorce because of extreme changes in sexual behavior and social disposition. Work induced divorce makes an employee develop a negative attitude towards his/her work. Sexual harassment weakens the support network and cut relationships between the victim and his/her social, professional or academic circles such as friends, colleagues, or family members. People may distance themselves from the victim or shun him or her accusing him/her of behaving in a manner that make her prone to sexual harassment. In analyzing the usefulness of Maslow' hierarchy of needs model to job satisfaction Nyanga et al. (2018) observed that love and belonging play a critical role in propelling job satisfaction, hence depriving workers love, and social ties ignite low job satisfaction.

\section{CONCLUSION AND RECOMMENDATIONS}

The study concluded that the government of Zimbabwe has put in place adequate and effective legislation that addresses almost all sexual harassment challenges at workplaces and encouraged organizations to put in place policies that combat if not eradicate sexual harassment at workplaces. To promote enforcement of the law related to sexual harassment, the government of Zimbabwe introduced platforms where workers can report all forms of sexual harassment activities at workplaces. The study also concluded that the way sexual harassment is defined and described differs from one trade to the other and also from one group of people to the other. The way the young workers, the single and divorced define it differs from the way the older and married workers define it. The way sexual harassment is defined by legislation in Zimbabwe is not the same way it is perceived by some workers in the construction industry. Some of the issues which the Acts regard as sexual harassment are viewed by some categories of workers as 'social professional' language and behavior that are normal for their trade. Despite the differences in definition the study however established that the prevalence of major sexual harassment activities was generally low across all the trades in the construction industry. It was also concluded that some forms of sexual harassment activities as defined by legislation were actually enhancers of job satisfaction. The study also concluded that there was a strong relationship between sexual harassment and job satisfaction. Sexual harassment impedes job satisfaction by creating psycho-social disorders in workers which consequently make workers dislike their work. Employees choose to stay at home than to work in sexually hostile work environments. Sexually hostile environments significantly affect employee performance, yet employee performance is a key antecedent to job satisfaction. It was also concluded that sexually harassed workers lose their jobs and income for refusing to accede to the sexual demands of the harassers. Sexual harassment is therefore unwanted 
and should not be tolerated by all the key stakeholders such as employers, trade unions and law enforcement agencies. It was recommended that organizations and the government should impose heavy sanctions on all the perpetrators of sexual harassment at workplaces. Organizations and arms of the government should investigate and report all sexual harassment cases at workplaces and punish all sexual harassers. Organizations should also develop explicitly clear sexual harassment policies which can deter sexual violence at workplaces. Lastly, organizations should also uphold the no tolerance to sexual harassment principle by making them vicariously liable for the sexual offences committed by their workers.

\section{REFERENCES}

American Association of University Women. 2006. Drawing the Line: Sexual Harassment on Campus. AAUW.

Arnqvist, G., \& Rowe, L. (2005). Sexual conflict. Princeton University Press.

Bingham, C., and Gansler, L.L. 2002. Class Action: The Landmark Case that Changed Sexual Harassment Law. New York, Anchor Books.

Boland M (2002). Sexual Harassment in the Workplace, Boston, Sphinx legal.

Dershowitz, A.K. \& Volokh (2009). Consequences of Mental Torture at the Workplace, Management Review, 13 (3), 1-14.

Kamir, O. 2005. Israel's 1998 Sexual Harassment Law: Prohibiting Sexual Harassment, Sexual Stalking, and Degradation Based on Sexual Orientation in the Workplace and in all Social Settings. International Journal of Discrimination and Law, 7, 315-336.

Markson, H.P (2017). Sexual Assault: A Threat workplace Harmony and Peace, Journal of Business Management 28 (1), 67-75.

Medgyesi, M., \& Zólyomi, E. (2016). Job satisfaction and satisfaction in financial situation and their impact on life satisfaction. European Commission, Directorate general for employment, social affairs and inclusion, 6.

Nyanga, T. 2018. Examining the Usefulness of Job Satisfaction Theories in Armed Conflict Society. Amity Global Human Resource Management Review, 8(2), 40-48.

Nyanga, T., Mudhovozi, P., and Chireshe, R. 2012. Causes and Effects of Role Ambiguity as Perceived by Human Resource Management Professionals in Zimbabwe. Journal of Social Sciences, 30(3), 57-64. https://doi.org/10.1080/09718923.2012.1189300

Nyanga, T., Mudhovozi, P., Chireshe, R. \& Maunganidze, L. 2012. A Survey of Job Satisfaction of Employees at Higher Learning Institutions in Masvingo Province, Zimbabwe. The Anthroplogist 14(1), 31-49. https://doi.org/10.1080/09720073.2012.11891223.

Nyanga T. \& Sibanda R. (2019) Magnet that Truss Domestic Workers and Employers in Armed Conflict Societies: A Case of Mazoe in Changara District in Mozambique, Journal of Vietnam Academy of Social Sciences, 20 (4), 22-36.

Nyanga T., Sibanda, R. \& Kruger J.W. (2018) Financial Growth and Stability in Armed Conflict Society: Does Job Satisfaction Play a Role?, Amity Journal of Management Research, 3 (1), 27-39. 
Parmar, P. 2014. Influences of Sex, Age and Education on Attitudes towards Gender Inequitable Norms and Practices in South Sudan. Global Public Health: An International Journal for Research, Policy and Practice, 9 (7), 773- 786

Patel P., Gibson- Fall F., Sullivan R. \& Irwin R. 2017. Documenting Attacks on Health Workers and Facilities in Armed Conflicts. Bulletin of the World Health Organization, 95 (1), 71-81.

The Criminal Law of the Lagos State Art 262, Lagos, Nigeria.

The Labour Act, 2017 (Act No. 64 of 2017) of the South Sudan Republic.

The Labour Act Chapter 28: 01, Harare, Government of Zimbabwe.

The Constitution of Zimbabwe amendment number 21 of 2013. Harare, Government of Zimbabwe.

United Nations Mission in the Republic of South Sudan (2014), Conflict in South Sudan: A Human Rights Report, https://unmiss.unmissions.org 